\title{
Health Promotion in the Community Via an Intergenerational Platform: Intergenerational e-Health Literacy Program (I-HeLP)
}

\author{
Vivien Xi WU
}

\section{Abstract}

The increase in life expectancy and emphasis on self-reliance for older adults are global phenomena. As such, living healthily in the community is considered a viable means of promoting successful and active aging. Existing knowledge indicates the prevalence of health illiteracy among the older population and the impact of poor health literacy on health outcomes and health care costs. Nevertheless, e-health literacy is a critical issue for a rapidly aging population in a technology-driven society. Intergenerational studies reported that older adults enjoy engaging with younger people and benefit from the social stimulation by improved social behaviours, intergenerational social network, and participation.

An Intergenerational $e$-health Literacy Program (I-HeLP) is developed to draw upon the IT-savvy strength of the youth, and teach older adults to seek, understand and appraise health information from electronic sources and apply knowledge gained to address the health problem. I-HeLP is an evidence-based program, which provides comprehensive coverage on relevant health-related e-resources.

V. X. WU $(\bowtie)$

Alice Lee Centre for Nursing Studies, Yong Loo Lin School of Medicine, National University of Singapore, Singapore, Singapore e-mail: nurwux@nus.edu.sg
I-HeLP aims to engage youth volunteers to teach older adults regarding e-health literacy, and enhance older adults' sense of coherence, e-health literacy, physical and mental health, cognitive function, quality of life, and intergenerational communication. I-HeLP promotes social participation, health, and wellbeing of older adults, and empowers the younger generation to play an active role in society. Furthermore, I-HeLP aligns with the 'Smart Nation' initiative by the Singapore government to empower citizens to lead meaningful and fulfilled lives with the use of technology.

\section{Keywords}

Attitude towards the older generation Community-dwelling older adults · e-Health literacy $\cdot$ Empathy $\cdot$ Empower younger generation - Health promotion in the community · Intergenerational communication Reliable health-related e-resources

Salutogenesis · Youth volunteer

\subsection{Introduction}

Improved living conditions, medical technology, and health services increase the life expectancy of people. The United Nations [1] reported that 
only $8 \%$ of the world's population were aged 60 and above in 1950; it increased to $12 \%$ by 2013 , and is expected to rise to $21 \%$ by 2050 . The global increase in life expectancy has made aging a political and economic issue as increased longevity raises social concerns about rising health care costs. Community-dwelling older adults are defined by those aged 60 years and above and living independently in a community [2]. Some older adults may live healthily in a community, but others may suffer from a large variety of health care problems, ranging from just getting older to specific medical conditions such as stroke, diabetes, osteoarthritis, or dementia.

World Health Organisation's active aging framework encourages the public and practitioners to 'support and value the process of optimising opportunities to maintain and enhance physical, mental, and social health as well as independence and quality of life over the life course' [3]. In this emerging paradigm, there is increasing pressure on older adults to keep themselves active and independent-physically, mentally and socially-in their communities, and cope with chronic health conditions and other challenges in late life [4]. The increase in life expectancy and emphasis on self-reliance for older adults are global phenomena. As such, living healthily in the community is considered a viable means of promoting successful and active aging.

\subsection{Background and Literature Review}

\subsubsection{Benefits of Intergenerational Interaction}

Intergenerational studies reported that older adults enjoy engaging with younger people, and that they benefit from the social stimulation [5]. Research indicates that older adults often participate in lifelong learning programs based on their interest and interaction with others [6]. These are often similar motivations for older adults who choose to engage in intergenerational learning projects [7]. Emerging evidence shows that intergenerational programs are significantly associated with subjective wellbeing in terms of boosting the quality of life, health status and life satisfaction [8]. Jenkins' study [8] shows that participation in these programs brings intrinsic enjoyment and provides opportunities to get out and socialise. The results of the intergenerational study indicate improved social behaviours, intergenerational social network scores and intragenerational social support, and increased social participation [9].

\subsubsection{E-Health Literacy}

Health literacy is the degree to which individuals have the capacity to obtain, process, and understand basic health information and services needed to make appropriate health decisions [10]. Building on this definition, the concept of e-health is being promoted intensively with the wide use of information technology. E-health literacy is the ability to seek, find, understand and appraise health information from electronic sources and apply the knowledge to address a health problem [11]. Existing knowledge indicates the prevalence of health illiteracy among the older population and the impact of poor health literacy on health outcomes and health care costs. Nevertheless, e-health literacy is a critical issue for a rapidly aging population in a technology-driven society. Literatures illustrate that intergenerational programs could contribute to the wellbeing of older adults holistically [9]. Herein, we describe an intergenerational e-health literacy program developed to draw upon the IT-savvy strength of youth teaching older adults to enhance their abilities to seek and appraise electronic health information.

\subsubsection{Empathy and Attitudes Towards Older Adults}

Empathy is the ability to identify and share emotions of others, and feel concerns when others are in distress [12]. Regardless of age, empathy is one of the key factors that affects one's social interaction and communication with other people [13, 14]. Rapid growth of aging population changes socio-structural dynamics [15]. Enlarged aging 
population might increase intergenerational prejudice and tension between younger and older generation [15]. Negative stereotypes towards older adults do exist, including the portraying of older adults as being lack of independence, less contributing, more fragile and forgetful [16]. Gradually, the older adults tend to accept the stereotypes and may develop low self-esteem [16]. During the process of self-stereotyping, older adults may experience failing memory, decreasing cognition, frailty, and even cardiovascular symptoms as a result of feeling stressed [17].

As a reflection, the younger generation may develop negative attitudes towards older adults due to the stereotypes, even despite having initially had positive attitudes towards the older generation [18]. Studies reported both younger and older generation could experience negative feelings during intergenerational communications and interactions $[19,20]$. However, with more contact with older adults, youth has been shown to develop more empathy and positive attitudes towards older adults [21]. Hence, intergenerational programs could also reshape the attitude and perception of the younger people towards older generation.

\subsection{Conceptual Framework}

The salutogenesis health model focuses on promoting individuals' health rather than the traditional risk and prevention focus which are central in the pathogenesis paradigm [22]. The salutogenic approach leads to a profound understanding through reflection on life situations and review of available resources and active adaptation to a stress-rich environment [23]. The key concepts in salutogenesis consists of Generalized Resistant Resources (GRRs) and Sense of Coherence (SOC). GRRs are protective factors, such as knowledge and social support. The individual could better cope with life stressors with enhanced GRRs [24]. By interacting with youth volunteers during e-health literacy program, community-dwelling older adults can improve their mental and cognitive wellbeing, as well as their intergenerational communication. The e-health literacy program creates opportunities for older adults to have more social contact and make commitments $[25,26]$. It promotes the sense of belonging and social inclusion for older adults, which could lead to a greater sense of life's meaningfulness [27].

SOC is a dispositional orientation of life described as perceived as comprehensive, manageable and meaningful, influencing how people think and behave by utilising the resources they have [24]. SOC comprises three core components: comprehensibility, manageability and meaningfulness. An individual with well-developed SOC is able to enhance his/her health by reducing the exposure to emotional and physiological stressors. SOC could be developed over time through empowering people with knowledge, experience, and perceived meaning-in-life, and utilising appropriate resources to minimise negative impacts on health [23]. The e-health literacy program provides a platform for older adults to access to GRRs, which is positively related to SOC, health condition and quality of life [26]. SOC plays an important role in the mental health and quality of life of older adults.

An Intergenerational $e$-health Literacy Program (I-HeLP) will be developed and evaluated. I-HeLP aims to promote intergenerational interaction between older adults and youth volunteers who teach them e-health. I-HeLP is an innovative program as it is guided by the salutogenic framework and integrates the concept of e-health literacy and intergenerational interaction which promotes social participation, health and wellbeing of older adults, and empowers the younger generation to play an active role in the society. Furthermore, I-HeLP aligns with the 'Smart Nation' initiative by the Singapore government to empower citizens to lead meaningful and fulfilled lives with the use of technology [44]. The notion of 'Smart Nation' opens up new possibilities to enhance the way we live, work and interact, and supports better living and stronger communities. Health and enabled aging are identified as one of the key domains, and government has put in place the infrastructure, policies, and enablers to encourage innovation [44].

In summary, salutogenesis promotes health in the community. Besides benefiting for the older adults, I-HeLP provides a platform for the youth to work with older adults and empowers 


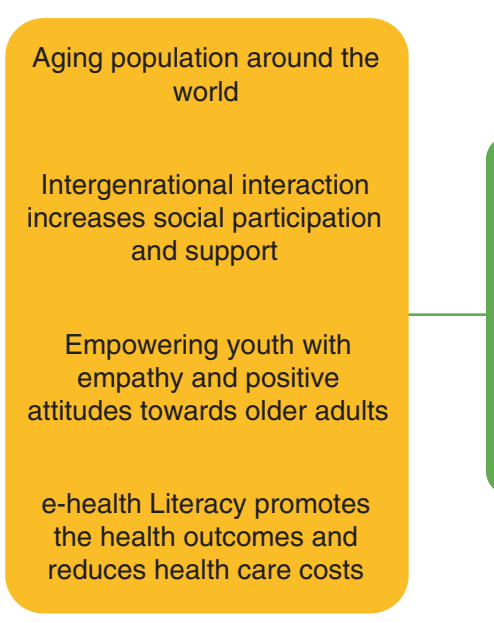

Intergenerational e-health Literacy Program (I-HeLP)

\section{Older Adults}

1. Improves Sense of Coherence

2. Increases e-health Literacy

3. Better Cognitive and Mental Health

3. Higher Quality of Life

4. Better Intergenrational Communication

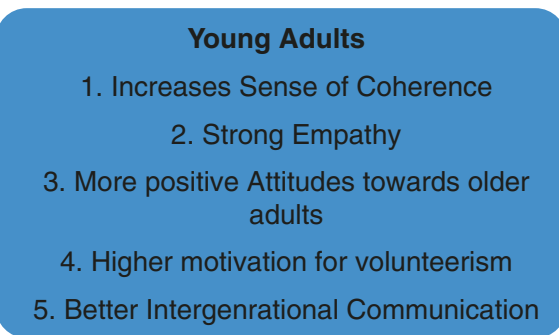

Fig. 24.1 Conceptual framework-salutogenesis

the youth with empathy and positive attitudes towards older adults. In a long run, the e-health literacy program promotes health outcomes and reduces health care costs. The impact of I-HeLP is twofold: (1) for older adultsimproves sense of coherence, cognitive and mental health, increase e-health literacy, quality of life, and intergenerational communication; (2) for young adults-improves sense of coherence, more positive attitudes towards older adults, increase empathy, motivation for volunteerism, and intergenerational communication (Fig. 24.1).

\subsection{Formative Design of the Intervention: I-HeLP}

This intervention is designed through a threephase iterative, client-centred participatory action research process [28]. First, a front-end analysis is conducted via focus groups and literature search to identify the unique health care needs of older adults and to formulate initial design ideas. Second, a preliminary design of the intervention is developed from literatures and focus group results. Finally, revisions and refinements are iteratively incorporated based on client-centred feedback which has been collected during usability sessions.

\subsubsection{Phase 1: Front-End Analysis}

A comprehensive search and evaluation of the existing e-health literacy interventions are carried out. The evaluation from the evidence-based literatures provides the fundamental understanding of current interventions. The research team conducts focus groups with older adults to explore their needs with regards to e-health. As an initial step, the research team in the university and the management team of Senior Activity Centres (SAC) had regular meetings and discussed the preliminary contents of I-HeLP and the methods of delivery.

\subsubsection{Phase 2: Design and Development}

The evaluation of literatures and focus groups findings in Phase 1 are centred on developing the contents of I-HeLP. Information gleaned from focus groups with older adults, and team design meetings are applied for the development of I-HeLP. Based 
on client-centred design suggestions, the following principles guide the development of I-HeLP: (1) the intervention must be designed for older adults; (2) content must be related to the specific e-health deficits that were identified during focus group and literature evaluations; (3) the content needs to be delivered in a brief and bite-size format to fit the attention span and cognitive capabilities of the older adults. A Content Expert Committee is formed which consists of two SAC managers who specialise in elder care, two researchers and one Advance Practice Nurse who specialises in Geriatrics. The Content Expert Committee reviewed the contents of I-HeLP and provided comments and feedback. The research team revised the contents based on the feedback.

\subsubsection{Pedagogical Considerations}

Pedagogical decisions are driven by unique needs revealed in Phase 1 focus groups. The intervention is designed to provide a platform for older adults to seek, find, understand and appraise health information from electronic sources and apply the knowledge to address their health problem. It is imperative to include instruction that promotes self-efficacy and motivation for the older adults. Interactive game sessions are used as a platform for hands-on practice to help the older adults to revise the contents. These features of I-HeLP meet the need of older adults and engage content that are not overly didactic in nature. In addition, the concepts of universal design for learning are applied to cater to the needs of the older adults. Not only is information presented in multiple formats and mediums (e.g. video, interactive content, imagery, and games), participants are also able to use various outlets of expression and/or action throughout the intervention.

\subsubsection{Phase 3: Formative, User-Centred Evaluation}

Formative evaluation takes the form of multi-modal usability testing [29, 30] which seeks to elicit feedback on applicability, content, ease-of-use, acceptance, and time to completion of modules. We collect feedback on the usage of information from the participants during the development of the intervention and during usability testing, which subsequently are used to further extend and refine the intervention [31]. The formative evaluation generates inputs regarding revisions and modifications that inform the design and development of I-HeLP.

\subsection{Outline of Intergenerational e-Health Literacy Program}

I-HeLP is developed to promote older adults' intellectual activities and engagement with youth regularly and cyclically through weekly learning and interacting session. The contents of the program are developed based on literature reviews $[32,33]$. The outline of I-HeLP is illustrated in Table 24.1.

Table 24.1 Outline of the intergenerational e-health literacy program (I-HeLP)

\begin{tabular}{|c|c|c|}
\hline Session & $\begin{array}{l}\text { Types of activity/ } \\
\text { duration }\end{array}$ & $\begin{array}{l}\text { Expected learning } \\
\text { outcomes }\end{array}$ \\
\hline 1 & $\begin{array}{l}\text { - Computer and } \\
\text { Internet basics } \\
\text { - Access health } \\
\text { information } \\
\text { websites } \\
\text { - Practice }\end{array}$ & $\begin{array}{l}\text { - Master the basic } \\
\text { knowledge of operating } \\
\text { a computer and } \\
\text { accessing the Internet } \\
\text { - Use the internet to } \\
\text { search for health- } \\
\text { related information on } \\
\text { the recommended } \\
\text { websites, e.g. Ministry } \\
\text { of Health, Health } \\
\text { Promotion Board, and } \\
\text { the various hospitals } \\
\text { - Navigate those } \\
\text { recommended } \\
\text { health-relevant } \\
\text { websites } \\
\text { - Search for a health- } \\
\text { related topic } \\
\text { - Find answers to } \\
\text { health-related questions }\end{array}$ \\
\hline 2 & $\begin{array}{l}\text { - Browse through } \\
\text { health } \\
\text { information } \\
\text { websites FAQs, } \\
\text { Videos Quizzes } \\
\text { - How to use } \\
\text { Health-related } \\
\text { Apps on mobile } \\
\text { devices } \\
\text { - Practice }\end{array}$ & $\begin{array}{l}\text { Learn how to: } \\
\text { - Use the Frequently } \\
\text { Asked Questions, } \\
\text { - Search for the videos } \\
\text { and view the } \\
\text { appropriate video } \\
\text { - Download and use of } \\
\text { Health-related Apps } \\
\text { - Use the quizzes and } \\
\text { practice the questions }\end{array}$ \\
\hline
\end{tabular}

(continued) 
Table 24.1 (continued)

\begin{tabular}{|c|c|c|}
\hline Session & $\begin{array}{l}\text { Types of activity/ } \\
\text { duration }\end{array}$ & $\begin{array}{l}\text { Expected learning } \\
\text { outcomes }\end{array}$ \\
\hline 3 & $\begin{array}{l}\text { Browse through } \\
\text { Ministry of } \\
\text { Health, and } \\
\text { Health } \\
\text { Promotion } \\
\text { Board, Health } \\
\text { Hub, Singapore } \\
\text { websites } \\
\text { Practice }\end{array}$ & $\begin{array}{l}\text { Learn how to: } \\
\text { - Find information about } \\
\text { doctors, hospitals and } \\
\text { clinics } \\
\text { - Search for health care } \\
\text { cost } \\
\text { - Search for health care } \\
\text { schemes and subsidies } \\
\text { - Search for healthy } \\
\text { choices food } \\
\text { - Search for physical } \\
\text { activities program } \\
\text { - Use the various health } \\
\text { screening program }\end{array}$ \\
\hline 4 & $\begin{array}{l}\text { Evaluating the } \\
\text { reliability of the } \\
\text { health } \\
\text { information } \\
\text { websites } \\
\text { - Practice }\end{array}$ & $\begin{array}{l}\text { Learn to recognise } \\
\text { - Reliable health } \\
\text { information websites } \\
\text { - Purpose of a health } \\
\text { information website } \\
\text { - Reviewers of a health } \\
\text { information website } \\
\text { - Most recent update of } \\
\text { health information } \\
\text { - Clues about the } \\
\text { accuracy of health } \\
\text { information website } \\
\text { - Contacts for a health } \\
\text { information website }\end{array}$ \\
\hline
\end{tabular}

\subsubsection{Implementation Plan}

I-HeLP is delivered over a period of 4 weeks. The program consists of preparation of the youth volunteers and implementation of the Intergenerational $e$-health Literacy Program.

\subsubsection{Part 1: Preparation of the Youth Volunteers}

The workshop aims to equip the youth volunteers with knowledge and skills to function as trainers to conduct teaching for older adults. Subsequently, the youth volunteers can carry out hands-on practical sessions to guide the older adults to access and browse through the relevant health-related websites. The intensive workshop for the youth volunteers focuses on relevant health-related websites, communication skills to promote effective intergenerational interactions with older adults, basic knowledge of older adults' usual life, and rules and regulations as a volunteer. Two Junior College students have joined the research team as interns and they have brought in a significant perspective in the development of the contents for the youth volunteer training workshop, since they are of the same age group as the youth volunteers.

\subsubsection{Part 2: Intergenerational e-health Literacy Program}

I-HeLP is carried out for the subsequent 4 weeks, one session $(2 \mathrm{~h})$ per week, whereby the youth volunteers will visit SAC in groups of 5-6. During the sessions, they will teach and guide the older adults to access, understand and appraise health information from reliable health-related websites.

\section{Mode of Delivery}

Face-to-face workshops are conducted for the older adults during the training program at the SAC. The youth volunteers would conduct a short teaching on the specific topic for each session, which is followed by individual guidance and practice with the older adults. Interactive games are utilised throughout the session to keep the older adults engaged. The workshop applies small group teaching technique to meet the learning needs of the older adults. Each session engages $8-10$ older adults and 5-6 youth volunteers (with the ratio of 1 volunteer to 2 older adults, providing close guidance). During the face-to-face sessions, the older adults could interact with their peers, the youth, and provide inputs about the program with the researchers.

\subsubsection{Plan for Program Evaluation}

Self-reported survey questionnaires will be used for the program evaluation. Outcome measures are used before and after the program to evaluate the effects of the I-HeLP. The outcome 
measures for older adults will include sense of coherence [34], e-health literacy [35], physical health, mental health (depression, anxiety) [36, 37], cognitive function [36], quality of life [38], and intergenerational communication [39]. Outcome measures for youth volunteers will include sense of coherence [34], empathy [40], attitudes towards older people [41], volunteerism [42], and intergenerational communication [43]. I-HeLP is planned to be conducted in the last quarter of 2020. Currently, the team is working on the development and refinement of the program. Data will be collected before and after the I-HeLP, and results of the research will be reported and published later.

\subsection{Conclusion}

I-HeLP aims to contribute to building capabilities in population health research and foster collaboration with the goal of translating evidence into action, offer important insights into the need for more intergenerational volunteer programs not only to promote social participation, health and wellbeing of older adults, but also to empower younger generation to play an active role in the society. The evaluation of I-HeLP will assist in understanding the effectiveness of such program in enhancing older adults' sense of coherence, e-health literacy, physical, mental health, cognitive function, quality of life, and intergenerational communication. I-HeLP may potentially be extended to a larger-scale in the communityliving environment.

\section{Take Home Messages}

- I-HeLP aligns with the 'Smart Nation' initiative by the Singapore government [44] to empower people to lead meaningful and fulfilled lives with the use of technology.

- I-HeLP aims to use technology to support the 'Smart Nation' initiative [44] to promote healthy and active aging and enhance the wellbeing of the older adults.
- I-HeLP develops partnerships among researchers, schools, communities, and health care organisations, which is critical to the successful adoption and implementation of health promotion programs.

- The partnership with SACs and schools represents an unprecedented opportunity to inform practice and policy at school, community and at national levels to promote healthy and active lifestyles among older adults, and thereby contribute to health and wellbeing of the elderly population in Singapore.

\section{References}

1. United Nations. Global issues: aging United Nations. 2017. http://www.un.org/en/sections/issues-depth/ ageing/.

2. Steultjens EMJ, Dekker J, Bouter LM, Jellema S, Bakker EB, Ende CHMVD. Occupational therapy for community dwelling elderly people: a systematic review. Age Ageing. 2004;33:453-60.

3. Butler-Jones D. The chief public health officer's report on the state of public health in Canada, 2010: growing older-adding life to years; 2010.

4. Narushima M, Liu J, Diestelkamp N. The association between lifelong learning and psychological wellbeing among older adults: implications for interdisciplinary health promotion in an aging society. Act Adapt Aging. 2013;37(3):239-50.

5. Dauenhauer J, Steitz DW, Cochran LJ. Fostering a new model of multigenerational learning: older adult perspectives, community partners, and higher education. Educ Gerontol. 2016;42(7):483-96.

6. Brady EM, Cardale A, Neidy JC. The quest for community in Osher Lifelong Learning Institutes. Educ Gerontol. 2013;39(9):627-39.

7. Underwood HL, Dorfman LT. View from the other side. J Intergener Relationsh. 2006;4(2):43-60.

8. Jenkins A. Participation in learning and wellbeing among older adults. Int $\mathrm{J}$ Lifelong Educ. 2011;30(3):403-20.

9. Fujiwara Y, Sakuma N, Ohba H, Nishi M, Lee S, Watanabe $\mathrm{N}$, et al. Reprints: effects of an intergenerational health promotion program for older adults in Japan. J Intergener Relationsh. 2009;7(1): 17-39.

10. Services USDoHaH, editor. Healthy people 2010: understanding and improving health. Washington, DC: U.S. Department of Health and Human Services; 2000 . 
11. Norman CD, Skinner HA. Eheals: the ehealth literacy scale. J Med Internet Res. 2006;8(4):e27.

12. Gould ON, Gautreau SM. Empathy and conversational enjoyment in younger and older adults. Exp Aging Res. 2014;40:60-80.

13. Bailey PE, Henry JD, Von Hippel W. Empathy and social functioning in late adulthood. Aging Ment Health. 2008;12:499-503.

14. Beedle J, Brown V, Keady B, Tranel D, Paradiso S. Trait empathy as a predictor of individual differences in perceived loneliness. Psychol Rep. 2012;110:3-15.

15. North MS, Fiske ST. An inconvenienced youth? Ageism and its potential intergenerational roots. Psychol Bull. 2012;138(5):982-97.

16. Nelson TD. Ageism: prejudice against our feared future self. J Soc Issues. 2005;61(2):207-21.

17. Levy BR, Leifheit-Limson E. The stereotypematching effect: greater influence on functioning when age stereotypes correspond to outcomes. Psychol Aging. 2009;24(1):230-3.

18. Cesario J, Plaks JE, Higgins ET. Automatic social behavior as motivated preparation to interact. J Pers Soc Psychol. 2006;90:893-910.

19. Williams A, Giles H. Intergenearaional conversations: young adults' retrospective accounts. Hum Commun Res. 1996;23:220-50.

20. Williams A, Garrett P. Communication evaluations across the life span: from adolescent storm and stress to elder aches and pains. J Lang Soc Psychol. 2002;21:101-26.

21. Schwalbach E, Kiernan S. Effects of an intergenerational friendly visit program on the attitudes of fourth graders towards elders. Educ Gerontol. 2002;28(3):175-87.

22. Antonovsky A. Health, stress and coping: new perspectives on mental and physical Well-being. San Francisco: Jossey-Bass; 1979.

23. Tan KK, Vehvilainen-Julkunen K, Chan WCS. Integrative review: salutogenesis and health in older people over 65 years old. J Adv Nurs. 2014;70:497-510.

24. Lindstrom B, Eriksson M. Contextualizing salutogenesis and Antonovsky in public health development. Health Promot Int. 2006;21(3):238-44.

25. Idan O, Eriksson M, Al-Yogon M. The salutogenic model: the role of generalized resistance resources. In: Mittelmark MB, Sagy S, Eriksson M, Bauer GF, Pelikan JM, Lindström B, et al., editors. The handbook of salutogenesis. Cham: Springer; 2017.

26. Koelen M, Erikkson M, Cattan M. Older people, sense of coherence and community. In: Mittelmark
MB, Sagy S, Eriksson M, Bauer GF, Pelikan JM, Lindström B, et al., editors. The handbook of salutogenesis. Cham: Springer; 2016.

27. Murayama Y, Ohba H, Yasunaga M, Nonaka K, Takeuchi R, Nishi M, et al. The effect of intergenerational programs on the mental health of elderly adults. Aging Ment Health. 2015;19(4):306-14.

28. Branch RM, Kopcha TJ. Instructional design models. In: Spector JM, Merrill MD, Elen J, Bishop MJ, editors. Handbook of research on educational communications and technology. New York: Springer; 2014. p. 77-87.

29. Krug S. Rocket surgery made easy: the do-it yourself guide to finding and fixing usability problems. New Riders: Canada; 2010.

30. Nielsen J. Usability engineering. Boston: Academic Press; 1994.

31. Dick W, Carey L. The systematic design of instruction. 3rd ed. Harper-Collins: New York; 1990.

32. Tse MM, Choi KC, Leung RS. E-health for older people: the use of technology in health promotion. Cyberpsychol Behav. 2008;11(4):63-71.

33. Xie B. Improving older adults' e-health literacy through computer training using $\mathrm{NIH}$ online resources. Libr Inf Sci Res. 2012;34(1):63-71.

34. Eriksson M, Lindstrom B. Validity of Antonovsky's sense of coherence scale: a systematic review. J Epidemiol Community Health. 2005;59(6): 460-6.

35. Chung SY, Nahm ES. Testing reliability and validity of the eHealth Literacy Scale (eHEALS) for older adults recruited online. Comput Inf Nurs. 2015; 33(4): 150.

36. Brown LM, Schinka JA. Development and initial validation of a 15-item informant version of the geriatric depression scale. Int J Geriatr Psychiatry. 2005;20(10):911-8.

37. Pachana NA, Byrne GJ, Siddle H, Koloski N, Harley E, Arnold E. Development and validation of the geriatric anxiety inventory. Int Psychogeriatr. 2007;16:103-14.

38. Power M, Quinn K, Schmidt S. World Health Organization quality of life-OLD group. Development of the WHOQOL-old module. Qual Life Res. 2005;14:2197-214.

39. Keaton SA, McCann RM, Giles H. The role of communication perceptions in the mental health of older adults: views from Thailand and the United States. Health Commun. 2017;32(1):92-102.

40. Spreng RN, Mckinnon MC, Mar RA, Levine B. The Toronto Empathy Questionnaire: scale development and initial validation of a factor-analytic solu- 
tion to multiple empathy measures. J Pers Assess. 2009;91(1):62-71.

41. Kogan N. Attitudes toward older people: the development of a scale and an examination of correlates. J Abnorm Soc Psychol. 1961;2(1):44-54.

42. Clary EG, Snyder M, Ridge RD, Copeland J, Stukas AA, Haugen J, et al. Understanding and assessing the motivations of volunteers: a functional approach. J Pers Soc Psychol. 1998;74:1516-30.

43. McCann RM. Intra- and intergenerational communication in the workplace: perspectives from Thailand and the United States of America; 2003.

44. Singapore SN. 2017. https://www.smartnation.sg/ about-smart-nation.

Open Access This chapter is licensed under the terms of the Creative Commons Attribution 4.0 International License (http://creativecommons.org/licenses/by/4.0/), which permits use, sharing, adaptation, distribution and reproduction in any medium or format, as long as you give appropriate credit to the original author(s) and the source, provide a link to the Creative Commons license and indicate if changes were made.

The images or other third party material in this chapter are included in the chapter's Creative Commons license, unless indicated otherwise in a credit line to the material. If material is not included in the chapter's Creative Commons license and your intended use is not permitted by statutory regulation or exceeds the permitted use, you will need to obtain permission directly from the copyright holder. 